\title{
Unidirectional Dual-Band CPW-Fed Antenna Loaded with an AMC Reflector
}

\author{
Qun Luo, Huiping Tian, Zhitong Huang, Xudong Wang, Zheng Guo, and Yuefeng Ji \\ The State Key Laboratory of Information Photonics and Optical Communications, School of Information \\ and Communication Engineering, Beijing University of Posts and Telecommunications, Beijing 100876, China
}

Correspondence should be addressed to Huiping Tian; hptian@bupt.edu.cn and Yuefeng Ji; jyf@bupt.edu.cn

Received 6 August 2013; Accepted 14 October 2013

Academic Editor: Francisco Falcone

Copyright (C) 2013 Qun Luo et al. This is an open access article distributed under the Creative Commons Attribution License, which permits unrestricted use, distribution, and reproduction in any medium, provided the original work is properly cited.

\begin{abstract}
A unidirectional dual-band coplanar waveguide fed antenna (DB-CPWFA) loaded with a reflector is presented in this paper. The reflector is made of an electric ground plane, a dielectric substrate, and artificial magnetic conductor (AMC) which shows an effective dual operational bandwidth. Then, the closely spaced AMC reflector is employed under the DB-DPWFA for performance improvement including unidirectional radiation, low profile, gain enhancement, and higher front-to-back (F/B) ratio. The final antenna design exhibits an $8 \%$ and $13 \%$ impedance bandwidths for $2.45 \mathrm{GHz}$ and $5.8 \mathrm{GHz}$ frequency regions, respectively. The overall gain enhancement of about $4 \mathrm{~dB}$ is achieved. The $\mathrm{F} / \mathrm{B}$ ratio is approximate to $20 \mathrm{~dB}$ with a $16 \mathrm{~dB}$ improvement. The measured results are inconsistent with the numerical values. The presented design is a suitable candidate for radio frequency identification (RFID) reader application.
\end{abstract}

\section{Introduction}

Over the past decade, radio frequency identification (RFID) technology is widely studied due to their tremendous applications. There are several frequency ranges assigned for this application such as $125 \mathrm{kHz}, 13.56 \mathrm{MHz}, 869 \mathrm{MHz}$, 902-928 MHz, $2.45(2.400-2.483) \mathrm{GHz}$, and 5.8 (5.7255.875) GHz [1]. Coplanar waveguide fed antenna (CPWFA) is well known as its wide bandwidth, light-weight, and ease of fabrication. What is more, CPWFA can easily achieve dualband performance [2-4]. All above make it a good candidate for RFID application. However, when the radiator and GND are printed on one side of the substrate, the energy will be radiated bidirectionally. Thus, the antenna gain is usually very low, and this could be seen from [2-4] showing general gain value of $2-4 \mathrm{dBi}$. This does not satisfy the requirement of many cases which require high gain and unidirectional radiation.

In order to improve the radiation performance for CPWFA, many efforts have been made. One of the typical methods is to put a reflector with an electric conducting surface at a distance of at least quarter-wavelength under the antenna [5], making it not suitable for low profile structure which requires overall height less than $\lambda / 10$ [6]. Artificial magnetic conductor (AMC) structure is famous for its property of in-phase reflection within a certain frequency range. Many researches are focused on the application of antennas loaded with AMC element to achieve low profile structure or to improve the impedance matching bandwidth [7-10]. The theory of achieving low profile structure could be illustrated in Figure 1. We can know that, by utilizing the AMC reflector, the space distance between the two structures could be reduced to a value smaller than free space wavelength $\lambda$.

In this paper, we extend the design of dual-band CPWFA based on AMC reflector to obtain a low profile and unidirectional radiation antenna. In contrast to many researches on single-band low profile antenna design [11-14], we focus on improving the radiation performance of the CPWFA within two operation band simultaneously. It is typically challenging since the mutual influence between the antenna and the reflector within two operation frequency range is complex. The major contribution for this paper is presenting a dualband CPWFA design loaded with a dual in-phase reflection 


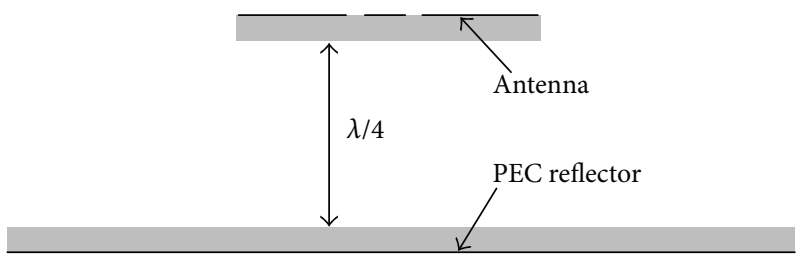

(a)

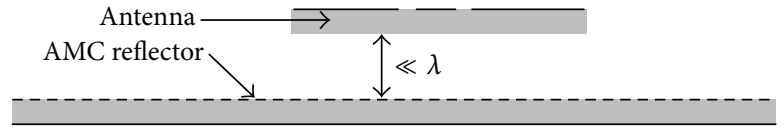

(b)

FIGURE 1: Illustration of the theory for antenna with (a) PEC reflector, (b) AMC reflector.

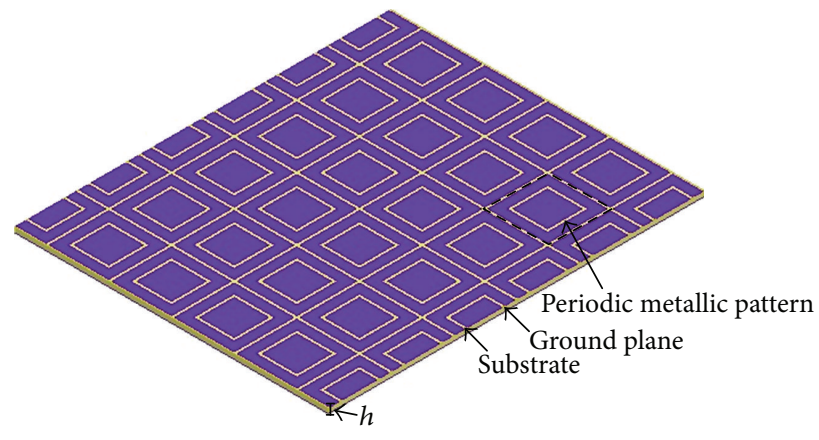

(a)

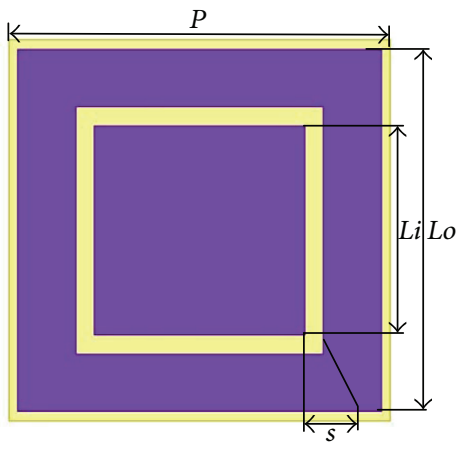

(b)

FIGURE 2: Layout of the AMC structure under investigation: (a) bird's eye view, (b) unit cell.

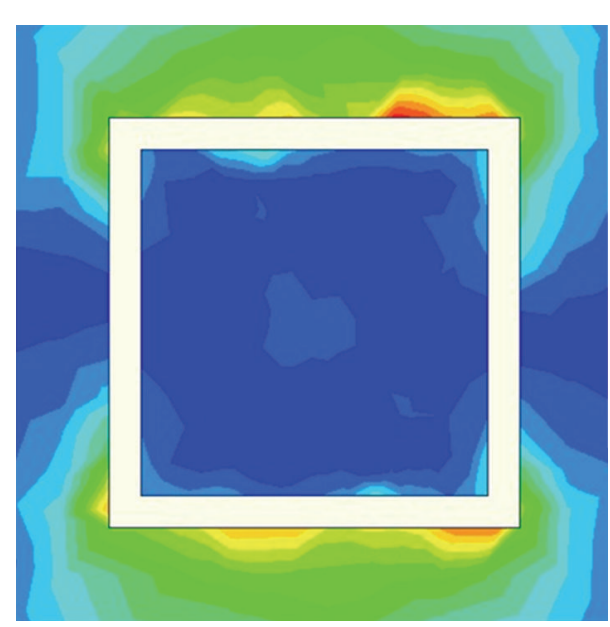

(a)

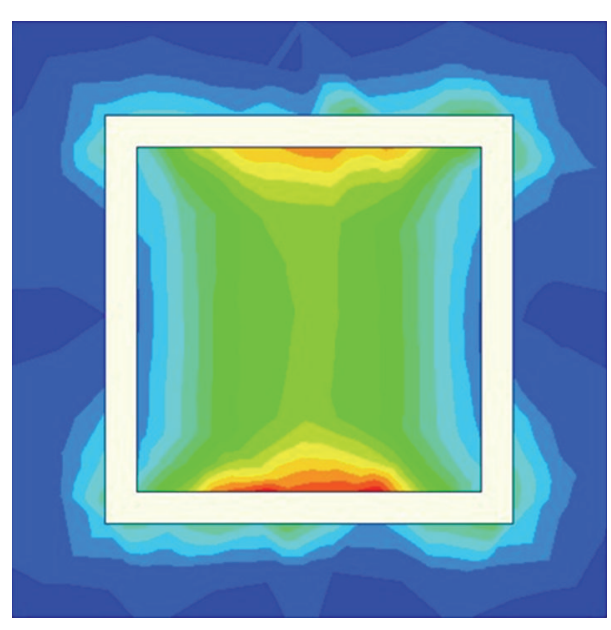

(b) $J_{\text {surf }}$ (A_per_m)

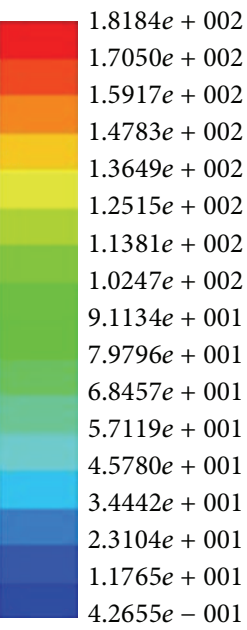

FIGURE 3: Surface current distribution of the dual-band AMC structure at (a) $2.45 \mathrm{GHz}$, (b) $5.8 \mathrm{GHz}$.

band AMC to achieve unidirectional radiation and lowprofile properties.

It is decided to design a novel low profile CPWFA loaded with an AMC reflector for two practical frequency range (2.42.484 $\mathrm{GHz}$ and 5.725-5.875 GHz) - that for RFID application. In Section 2, we describe the details on designing the AMC reflector which shows in-phase reflection within two frequency ranges. In Section 3, the designs of reference antenna and final structure are investigated, and the performances are analyzed. Then, the numerical and experimental results are investigated in Section 4. Finally, a conclusion is made in Section 5.

\section{Design of AMC Reflector}

2.1. Principle of Operation. There are many candidate structures for design of a dual in-phase reflection phase band AMC. One of the typical AMC structures is shown in [15]. A parasitic rectangle is added to achieve dual-band 


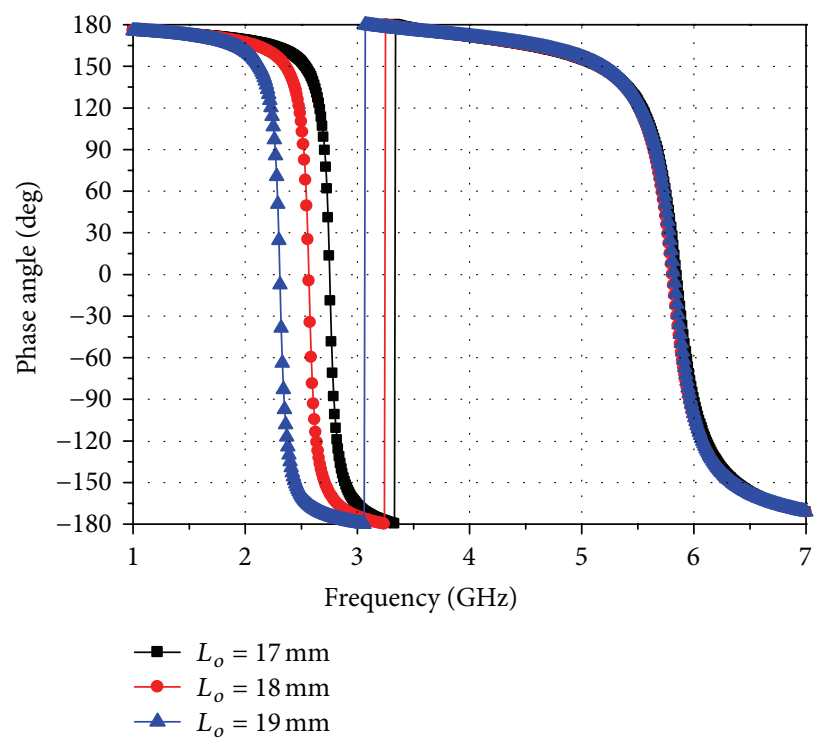

FIGURE 4: Effect of AMC parameter $L_{o}$.

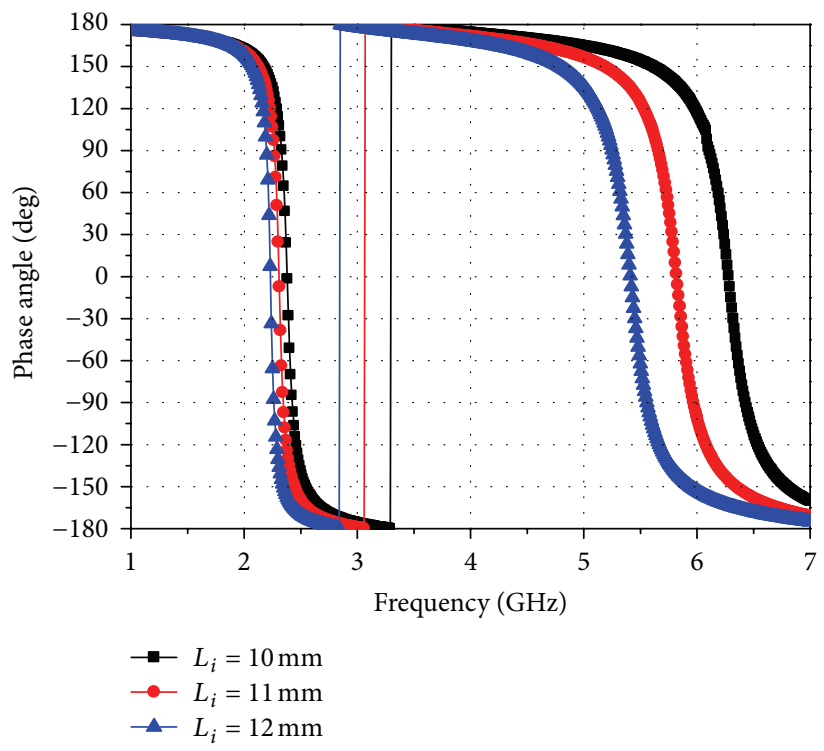

FIGURE 5: Effect of AMC parameter $L_{i}$.

performance as reported in [16]. The structure is shown in Figure 2. According to $[17,18]$, the structure can be equal to a parallel tuned $L C$ circuit. The overall resonance frequency can be estimated by

$$
f_{0}=\frac{1}{2 \pi \sqrt{L C}}
$$

where the overall capacity $C$ is produced by the gap between the patches and the patch itself with the current flow produces an inductance $L$. The structure resonates within the frequency range where the high impedance and in-phase reflection conditions occur. The surface impedance may be calculated by

$$
Z_{s}=\frac{j w L}{1-\left(w / w_{0}\right)^{2}}
$$

$w$ is given by

$$
w=2 \pi f
$$

Along with the above equations, it is useful to determine the AMC frequency range. For the purpose of low profile, the bandwidth of use is defined as the frequency range where the reflection phase is between $-90^{\circ}$ and $+90^{\circ}$. Therefore, when 


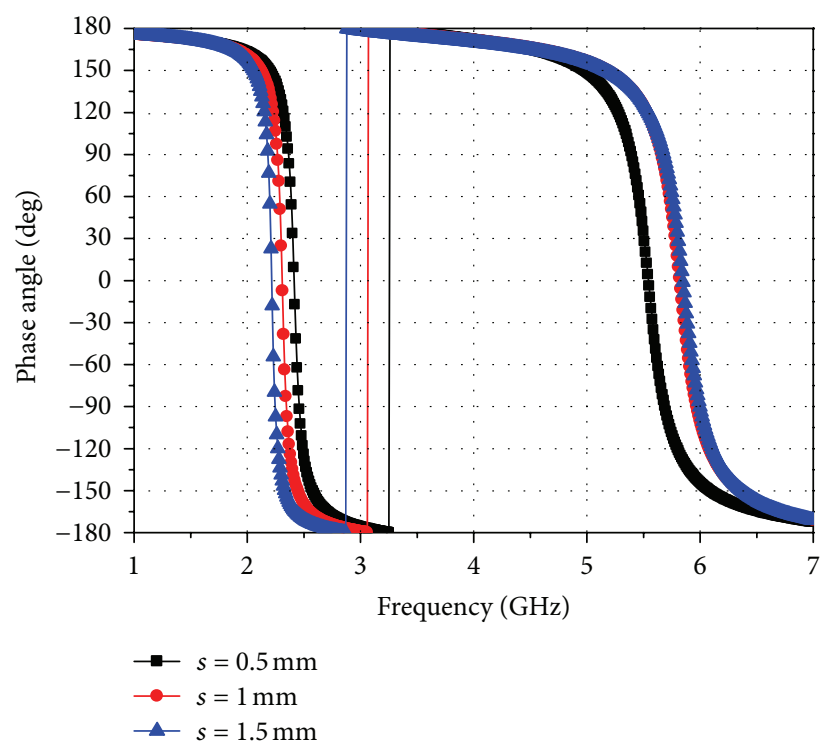

FIGURE 6: Effect of AMC parameter $s$.

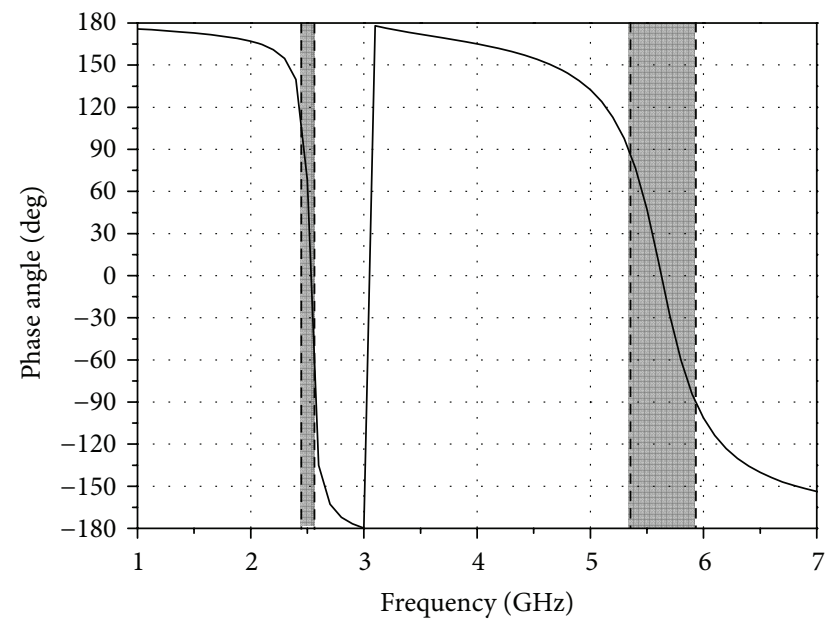

FIGURE 7: Reflection phase response for the uniplanar compact AMC structure.

the reflector is close to the antenna, the electric fields are added constructively.

The surface current distribution at $2.45 \mathrm{GHz}$ and $5.8 \mathrm{GHz}$ is plotted in Figures 3(a) and 3(b) respectively. It is shown that the surface current at $2.45 \mathrm{GHz}$ is mainly restricted in the parasitic patch, while the current at $5.8 \mathrm{GHz}$ primary lies in the inner patch. It can be concluded that the parasitic rectangle runs around the inner patch to make the structure resonate at the lower frequency, and the inner patch has a decisive impact on the higher resonant frequency.

2.2. Parameter Study. The structure is printed on the top of FR4 substrate with thickness $h=1.6 \mathrm{~mm}$, relative permittivity $\varepsilon_{r}=4.4$, and loss $\tan \theta=0.02$. At the bottom of the FR4 lies a PEC surface. As shown in Figure 2, $P$
TABLE 1: Parameters of the optimized AMC design.

\begin{tabular}{lcccc}
\hline Parameters & $P$ & $L_{o}$ & $L_{i}$ & $s$ \\
\hline Value $(\mathrm{mm})$ & 20 & 19 & 11 & 1 \\
\hline
\end{tabular}

represents the period of one unit cell, $L_{i}$ represents the length of inner patch, $s$ describes the gap between the inner patch and parasitic patch, $L_{o}$ is the length of parasitic patch, and the gap between the neighbor cell $g$ can be calculated by $P$ and $L_{o}$. Three key parameters $L_{i}, L_{o}$, and $s$ are analyzed, and the results are shown in this section.

The reflection phase versus frequency for different value of $L_{o}$ is shown in Figure 4 while the other parameters stay the same. The higher resonance frequency has few changes while the lower frequency shows a noteworthy difference. The resonance frequency moves towards the lower frequency as the $L_{o}$ increases. This is because with $L_{o}$ increasing, the gap between neighboring cells gets smaller, making the capacity effects more obvious which mainly determine the lower resonant frequency.

Figure 5 shows the results for the different lengths of inner patch $L_{i}$ which is varied from $10 \mathrm{~mm}$ to $12 \mathrm{~mm}$. Both lower and higher resonant frequency points are moving toward the lower frequency range as the increase of $L_{i}$, and the influence is especially distinct for the higher resonant frequency.

Figure 6 presents the influence of $s$. We can know that the lower resonant frequency is shifting towards the higher frequency while the $s$ is decreasing from $1.5 \mathrm{~mm}$ to $0.5 \mathrm{~mm}$. For the higher resonant frequency, the shift shows an opposite trend. The resonance frequency moves toward the lower frequency as the decrease of $s$.

With the guideline, we can tune the AMC structure to a suitable design. The parameters (seen in Figure 2) of the optimized design are listed in Table 1 . The final reflection phase response versus frequency is depicted in Figure 7. 


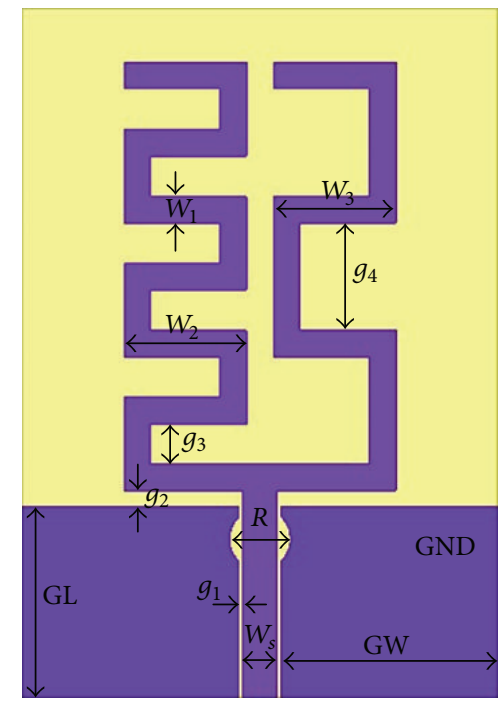

Figure 8: Configuration of reference dual-band antenna.

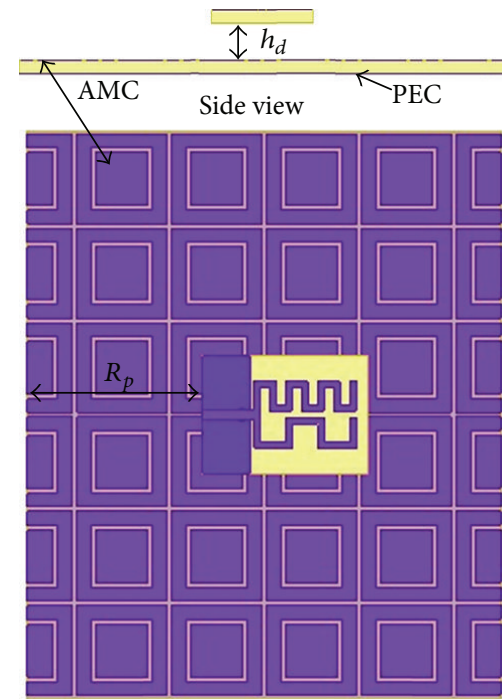

Top view

FIGURE 9: Configuration of antenna with an AMC reflector.

TABLE 2: Parameters of the optimized reference antenna design.

\begin{tabular}{lccccccccccc}
\hline Parameters & $w_{1}$ & $w_{2}$ & $w_{3}$ & $w_{s}$ & $\mathrm{GW}$ & $R$ & $g_{1}$ & $g_{2}$ & $g_{3}$ & $g_{4}$ & $\mathrm{GL}$ \\
\hline Value $(\mathrm{mm})$ & 1.3 & 6.4 & 6.4 & 1.8 & 11.4 & 1.4 & 0.2 & 0.8 & 2.1 & 5.5 & 10 \\
\hline
\end{tabular}

The in-phase frequency region is $2.38-2.60 \mathrm{GHz}$ and $5.30-$ $5.90 \mathrm{GHz}$ where the AMC surface shows a reflection phase in the range $\pm 90^{\circ}$. The two in-phase regions contain the RFID operation region of $2.45 \mathrm{GHz}$ and $5.8 \mathrm{GHz}$.

\section{Design of Low Profile Dual-Band Antenna}

3.1. Design of Reference Antenna. The antenna with a dualband property, which is reported in [19], is employed in this
TABLE 3: Comparison of F/B ratios for antenna 1 and antenna 3.

\begin{tabular}{lccccc}
\hline 2.45 GHz region $(\mathrm{GHz})$ & 2.35 & 2.4 & 2.45 & 2.5 & \\
\hline Antenna 1 $(\mathrm{dB})$ & 2.00 & 2.00 & 2.03 & 2.05 & \\
Antenna 3 $(\mathrm{dB})$ & 18.32 & 18.98 & 19.61 & 20.44 & \\
\hline $5.8 \mathrm{GHz}$ region & 5.65 & 5.7 & 5.75 & 5.8 & 5.85 \\
\hline Antenna 1 $(\mathrm{dB})$ & 2.57 & 2.20 & 2.03 & 2.16 & 2.22 \\
Antenna 3 $(\mathrm{dB})$ & 22.97 & 23.55 & 23.79 & 22.59 & 22.48
\end{tabular}

paper. We choose it as our reference antenna because of its compactness, simple structure, and wide bandwidth.

The reference antenna uses a meander technique. Two meander strips are loaded to achieve dual-band performance, and the electrical length of the meander strip is about $\lambda_{g} / 4$ 


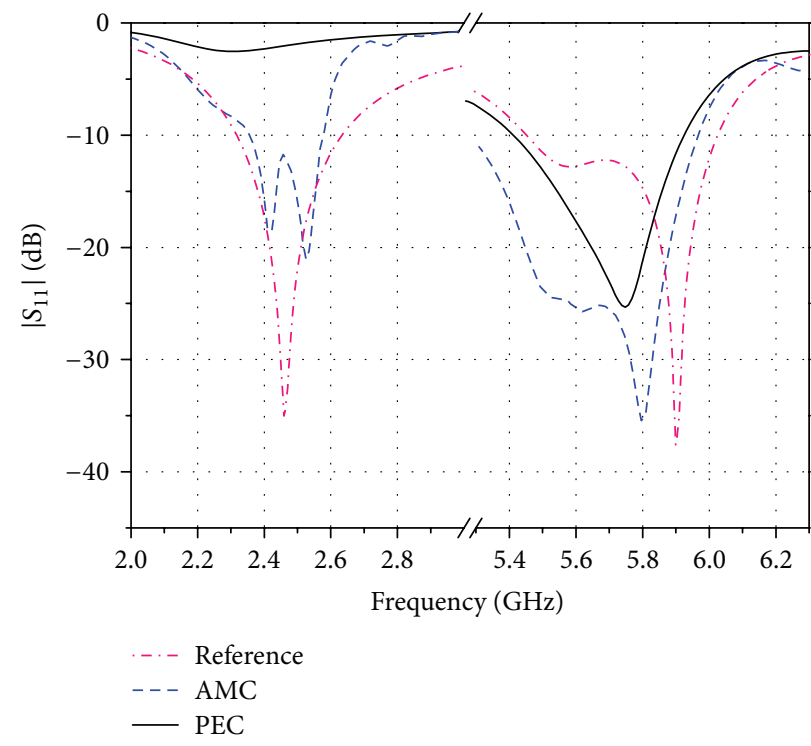

FIGURE 10: Comparison of $|S 11|$ between antenna with and without modified GND.

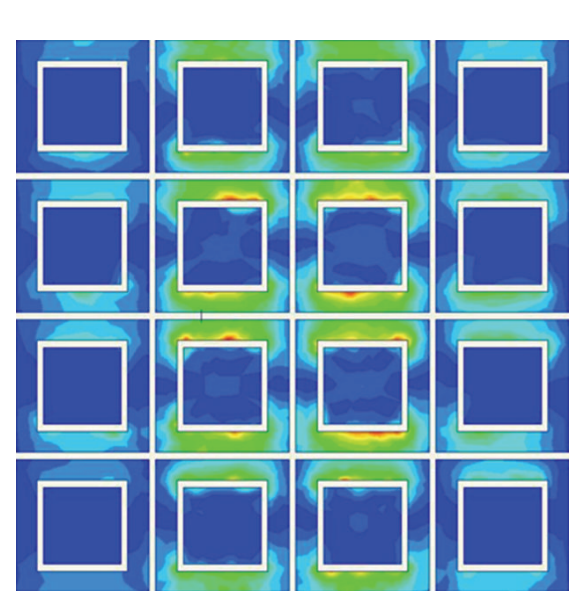

(a)
$J_{\text {surf }}($ A_per_m)

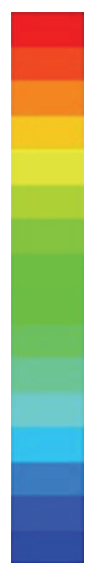

$7.3911 e+001$ $6.4678 e+001$ $6.0062 e+001$ $5.5445 e+001$ $5.0829 e+001$ $4.6212 e+001$ $4.1596 e+001$ $3.6980 e+001$ $3.2363 e+001$ $2.7747 e+001$ $2.3130 e+001$ $1.8514 e+001$ $1.3897 e+001$ $9.2810 e+000$ $4.6645 e+000$ $4.8095 e-002$
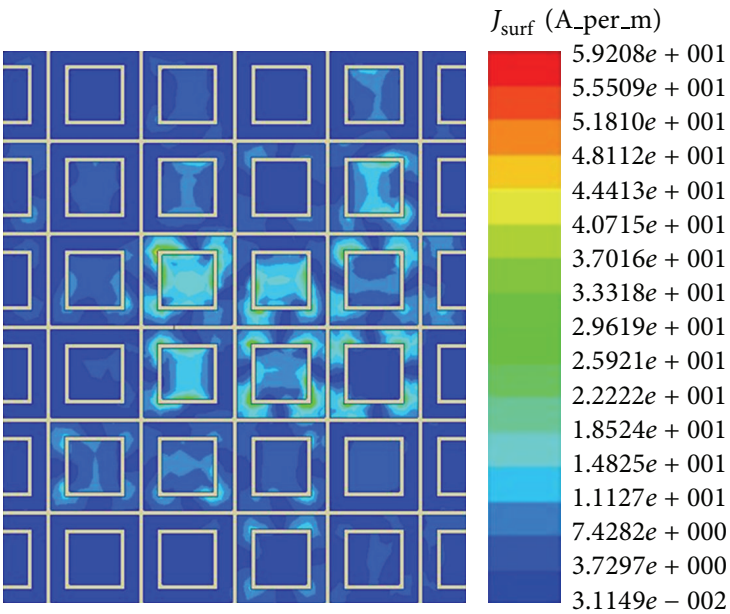

(b)

FIGURE 11: Surface current distribution of the AMC reflector with different dimension (a) $80 \mathrm{~mm} \times 80 \mathrm{~mm}$, (b) $100 \mathrm{~mm} \times 120 \mathrm{~mm}$.

to produce a resonance frequency. According to [2], by using two rectangular slots symmetrically on each side of feed line, the impedance match is much easier and can be improved significantly. In this paper, we cut two circular arc slots symmetrically to improve the impedance match. The configuration of the reference antenna is shown in Figure 8, which is under appropriate modification compared with [19]. The CPWFA is printed on the FR4 substrate, which is the same as the AMC substrate. The key parameters of the structure are noted in the figure and are listed in Table 2.

3.2. Design of Low Profile Dual-Band Antenna. In order to achieve unidirectional radiation performance, a reflector is added under the CPWFA. The design with an AMC reflector is described in Figure 9. The distance between the bottom of the antenna and the top of the reflector is $h_{d}=4 \mathrm{~mm}$. The distance between the edge of antenna and the edge of reflector is $R_{p}=7 \mathrm{~mm}$.

Figure 10 compares the simulated return loss of three kinds of dual-band antenna. The input impedance is matched to a $50 \Omega$ transmission line. For the reference CPWFA, the frequency region where reflection coefficient smaller than $-10 \mathrm{~dB}$ is $2.3-2.64 \mathrm{GHz}$ and $5.48-6.12 \mathrm{GHz}$. With the $\mathrm{PEC}$ reflector, the return loss of lower resonance frequency $2.45 \mathrm{GHz}$ is only $-3 \mathrm{~dB}$, which shows no appropriate operation bandwidth. This is because the PEC's reflection phase leading to an opposite direction of the image current compared with the original one. The antenna with an AMC reflector shows an operation bandwidth of $2.38-2.58 \mathrm{GHz}$ and $5.3-5.94 \mathrm{GHz}$.

We can learn from [9] that in order to reduce the leakage wave propagation, the surface current at the edge of reflector 


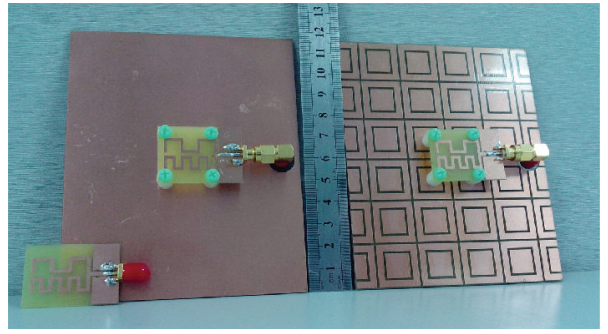

FIgURE 12: Photograph of three different antenna designs.

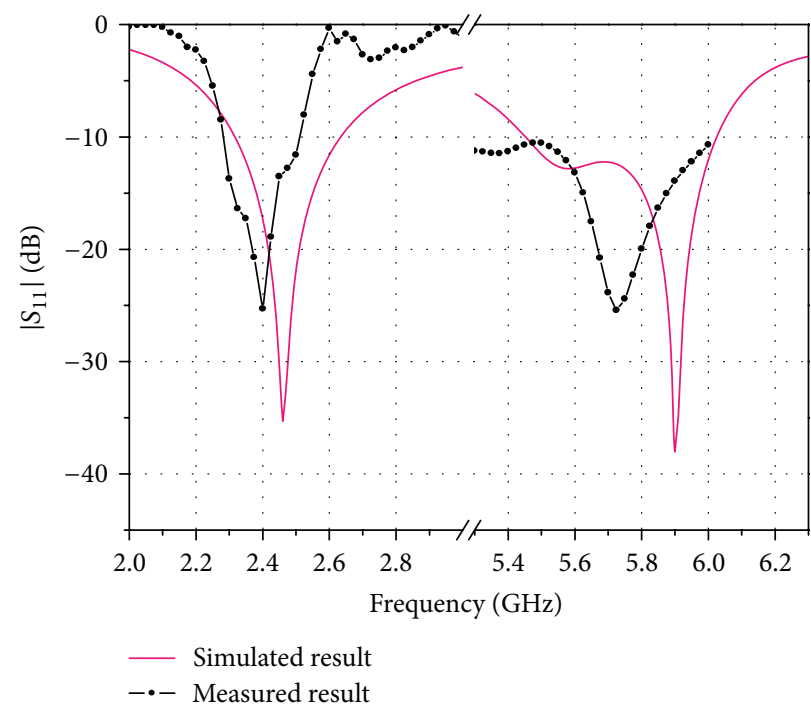

(a)

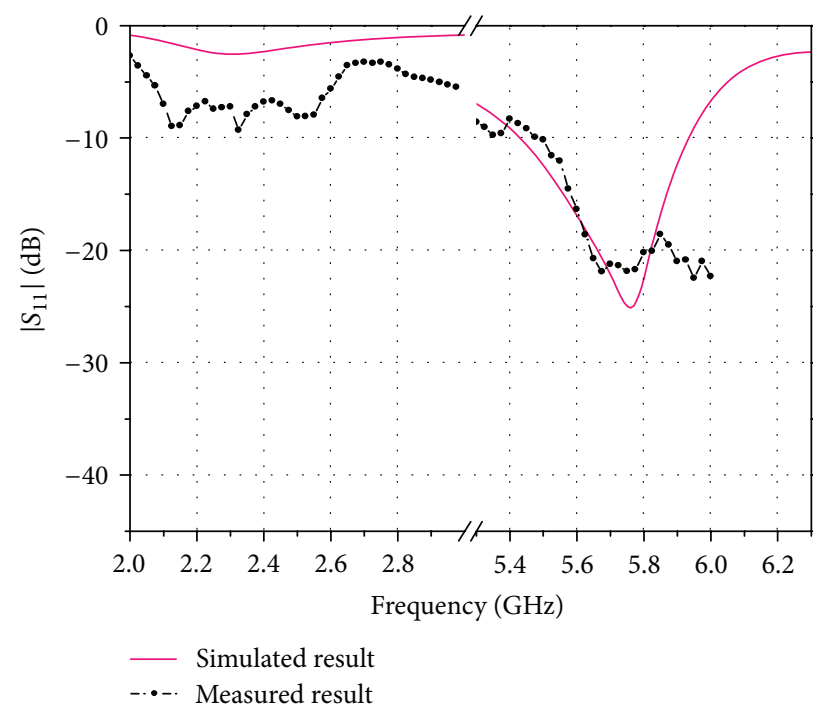

(b)

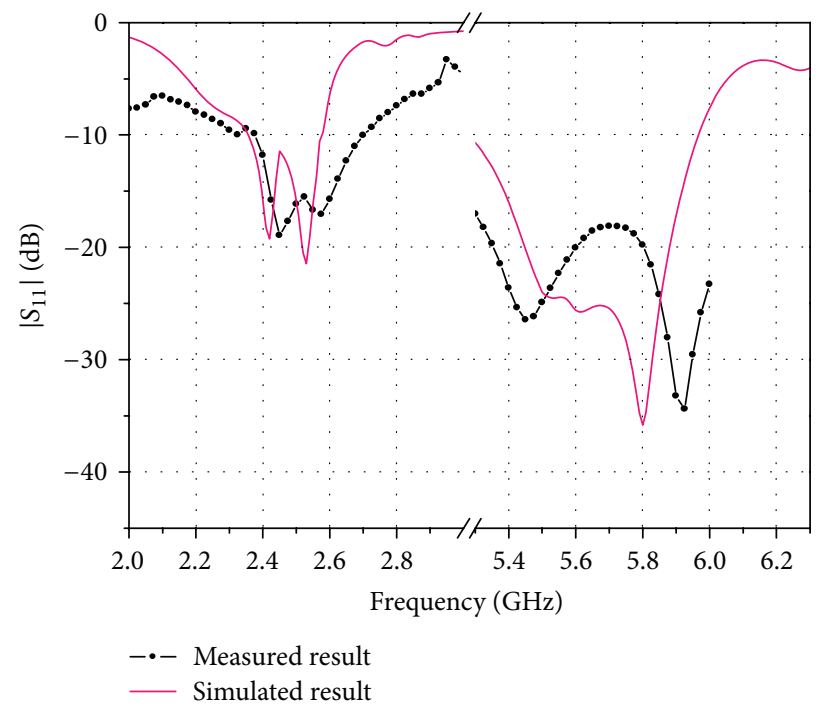

(c)

FIGURE 13: Measured and simulated $|S 11|$ for (a) reference antenna, (b) antenna with PEC reflector, and (c) antenna with AMC reflector.

should be reduced as much as possible. Figure 11 shows the surface current distribution on the AMC patch for different reflector dimensions. As can be seen, the current distribution at the edge of the bigger reflector is much less than that of the small reflector. The surface current at the edge of $100 \times$ $120 \mathrm{~mm}^{2}$ AMC reflector is about 0.05 of its maximum in the middle of the reflector. So the final reflector is with dimension of $100 \times 120 \mathrm{~mm}^{2}$. 


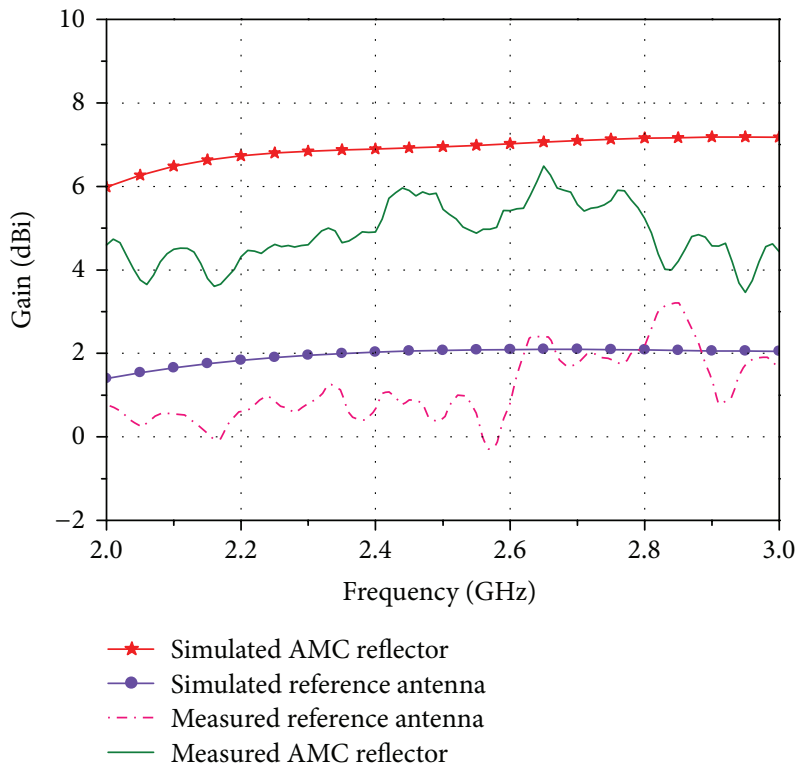

(a)

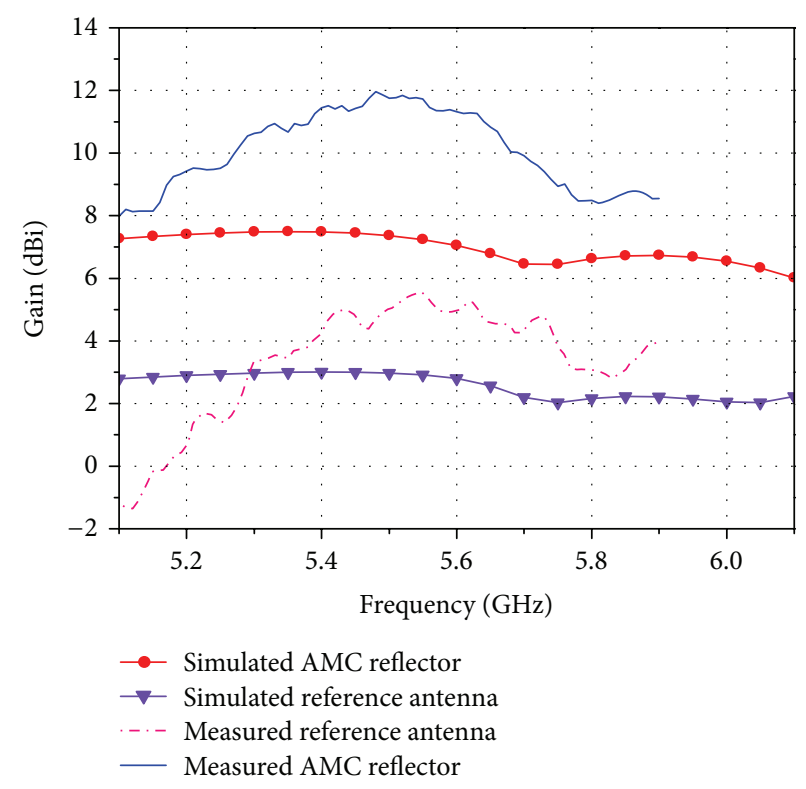

(b)

FIGURE 14: Measured and simulated gain for the reference design and final design (a) $2.45 \mathrm{GHz}$ frequency range, (b) $5.8 \mathrm{GHz}$ frequency range.

\section{Results and Discussions}

The experimental results are presented and analyzed in this section. The performances of antenna 1 (reference CPWFA), antenna 2 (antenna with PEC reflector), and antenna 3 (antenna with AMC reflector) are compared and discussed. The performances include impedance matching frequency band, peak gain, radiation pattern, and $\mathrm{F} / \mathrm{B}$ ratio.

Figure 12 describes the photograph of three antenna designs. The performance of far-field radiation measurements were carried out by Wireless Communications \& EMC Laboratory of BUPT. The measured frequency band ranged from $400 \mathrm{MHz}$ to $6 \mathrm{GHz}$ is limited by the test cable and adapter.

Figure 13 compares the measured and simulated $\left|S_{11}\right|$ of the three different antennas types. The $S$-parameter was measured using the Agilent $S$-parameter network analyzer $8753 \mathrm{ES}$ ranged from $30 \mathrm{kHz}$ to $6 \mathrm{GHz}$. According to Figure 13, the impedance bandwidth of measured results for $\left|S_{11}\right|<$ $-10 \mathrm{~dB}$ agrees well with that of the simulated structures. The little difference may be caused by the fabrication tolerance and possible effect of the measurement process.

The measured and simulated gain performances of two different designs for two operation bandwidth are presented in Figure 14. As for the simulated gain, the reference antenna is about $1.8-2.2 \mathrm{dBi}$ and $2-2.3 \mathrm{dBi}$ for $2.45 \mathrm{GHz}$ and $5.8 \mathrm{GHz}$ RFID bands. With the AMC reflector, the gain is improved to 6.9-7.1 $\mathrm{dBi}$ and $6.4-6.6 \mathrm{dBi}$. While coming to the measured gain, the reference antenna is about $0-2 \mathrm{dBi}$ for $2.45 \mathrm{GHz}$ frequency range and 3-5 $\mathrm{dBi}$ for $5.8 \mathrm{GHz}$ band, the result of the final design is improved to $5-6 \mathrm{dBi}$ and $8-10 \mathrm{dBi}$ for the two bands. Both the numerical and experimental results show that the gain enhancement can be up to more than $100 \%$ within the two operation bands.
Figure 15 depicts the comparison of radiation patterns for the final design and the reference design. The reference antenna can radiate bidirectionally while the final design shows unidirectional radiation patterns. The $\mathrm{F} / \mathrm{B}$ ratio for two types of antenna is compared in Table 3. It is shown that with the loaded AMC reflector, the front-to-back ratio is improved significantly.

All above verify the performance of unidirectional radiation for dual-band antenna structure.

\section{Conclusions}

The paper has demonstrated a coplanar antenna integrated with an AMC reflector. The final design is a low profile structure and shows unidirectional radiation at two operating RFID frequency region simultaneously. The integrated antenna has operating bandwidths of $8 \%$ at $2.45 \mathrm{GHz}$ and $13 \%$ at $5.8 \mathrm{GHz}$. Compared to conventional reflector antenna design, the profile for this structure can be reduced from $\lambda / 4$ to $0.03 \lambda$. The radiation performances, including antenna gain, radiation pattern, and front-to-back ratio, are significantly improved as a contrast to the reference coplanar antenna. The gain enhancement can be up to more than $4 \mathrm{~dB}$. Simulations and measurements are generally in good agreement. Overall, this paper gives directions for dualband antenna design which needs low profile and improved radiation performance.

\section{Conflict of Interests}

The authors declare that there is no conflict of interests regarding the publication of this paper. 

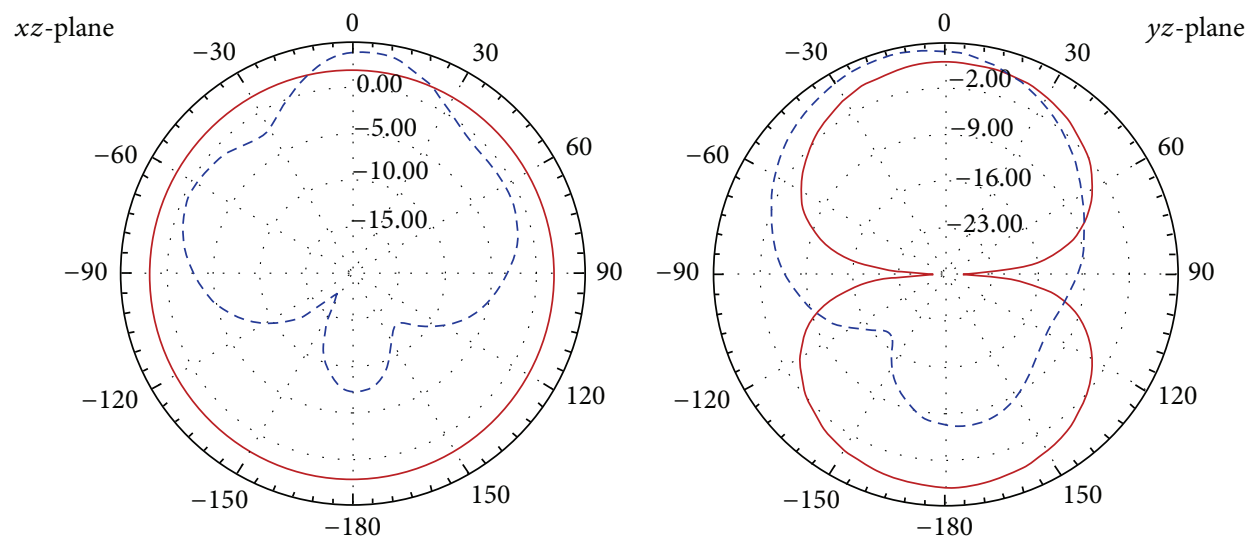

(a)
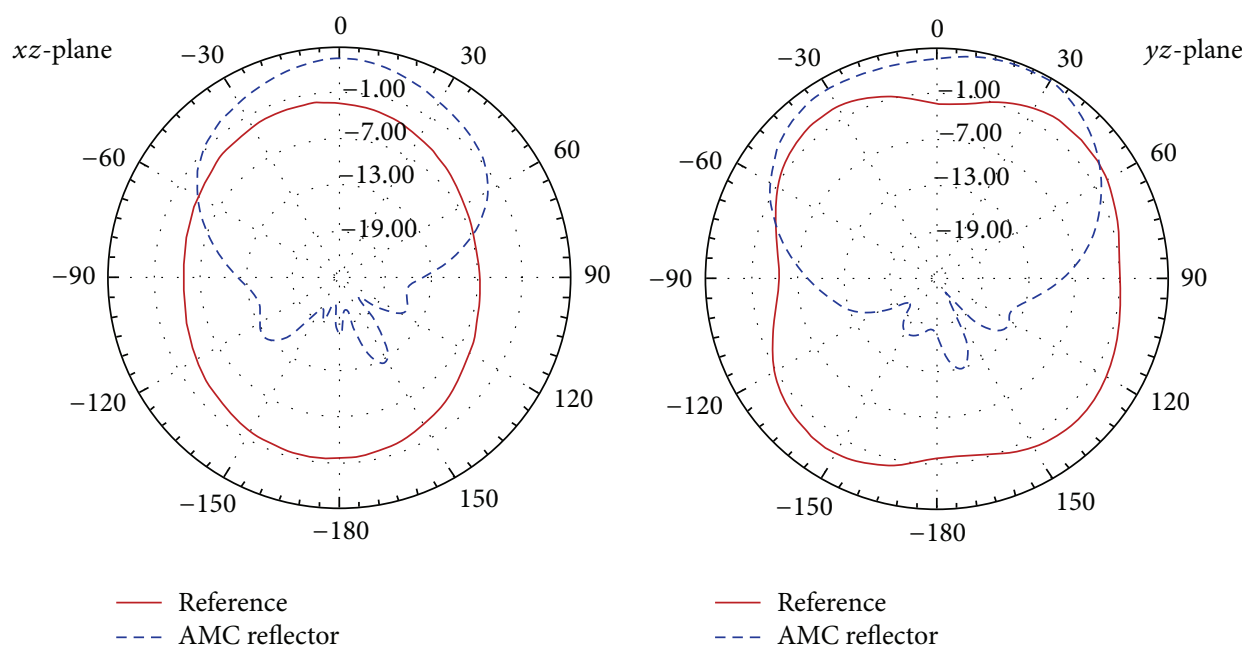

(b)

FIGURE 15: Radiation patterns for the reference antenna and the final design with an AMC reflector (a) $2.45 \mathrm{GHz}$, (b) $5.8 \mathrm{GHz}$.

\section{Acknowledgments}

This research was supported in part by National 973 Program (no. 2012CB315705) and National Science and Technology Major Project (no. 2010ZX03004-002-02). The authors are thankful for the great support of this work. The authors would also like to thank Wireless Communications \& EMC Laboratory, BUPT, for the gain measurements of the antennas.

\section{References}

[1] A. T. Mobashsher, M. T. Islam, and N. Misran, "A novel highgain dual-band antenna for RFID reader applications," IEEE Antennas and Wireless Propagation Letters, vol. 9, pp. 653-656, 2010.

[2] L. Hu and W. Hua, "Wide dual-band CPW-fed slot antenna," Electronics Letters, vol. 47, no. 14, pp. 789-790, 2011.

[3] C.-C. Lin, E.-Z. Yu, and C.-Y. Huang, "Dual-band rhombus slot antenna fed by CPW for WLAN applications," IEEE Antennas and Wireless Propagation Letters, vol. 11, pp. 362-364, 2012.

[4] Y. Seo, J. Jung, H. Lee, and Y. Lim, "Design of compact dualmeander antenna for WLAN operation," Microwave and Optical Technology Letters, vol. 54, no. 7, pp. 1595-1599, 2012.
[5] J. D. Kraus and R. J. Marhefka, Antennas: For All Applications, chapter 10, 3rd edition, 2002.

[6] F. Yang and Y. Rahmat-Samii, "Reflection phase characterizations of the EBG ground plane for low profile wire antenna applications," IEEE Transactions on Antennas and Propagation, vol. 51, no. 10, pp. 2691-2703, 2003.

[7] A. Pirhadi, H. Bahrami, and J. Nasri, "Wideband high directive aperture coupled microstrip antenna design by using a FSS superstrate layer," IEEE Transactions on Antennas and Propagation, vol. 60, no. 4, pp. 2101-2106, 2012.

[8] R. C. Hadarig, M. E. De Cos, and F. Las-Heras, "Microstrip patch antenna bandwidth enhancement using AMC/EBG structures," International Journal of Antennas and Propagation, vol. 2012, Article ID 843754, 6 pages, 2012.

[9] J. D. Lilly, W. E. McKinzie III, D. T. Auckland, and A. Humen Jr., "Capacitively-loaded bent-wire monopole on an artificial magnetic conductor," United States Patent, No. US 6768476, 2004 .

[10] M. S. Alam, N. Misran, B. Yatim, and M. T. Islam, "Development of electromagnetic band gap structures in the perspective of microstrip antenna design," International Journal of Antennas and Propagation, vol. 2013, Article ID 507158, 22 pages, 2013. 
[11] P. Jin and R. W. Ziolkowski, "High-directivity, electrically small, low-profile near-field resonant parasitic antennas," IEEE Antennas and Wireless Propagation Letters, vol. 11, pp. 305-309, 2012.

[12] F. Yang and Y. Rahmat-Samii, "A low-profile circularly polarized curl antenna over an electromagnetic bandgap (EBG) surface," Microwave and Optical Technology Letters, vol. 31, no. 4, pp. 264-267, 2001.

[13] A. Ourir, A. De Lustrac, and J.-M. Lourtioz, "All-metamaterialbased subwavelength cavities $(\lambda 60)$ for ultrathin directive antennas," Applied Physics Letters, vol. 88, no. 8, Article ID 084103, 2006

[14] J. Joubert, J. C. Vardaxoglou, W. G. Whittow, and J. W. Odendaal, "CPW-fed cavity-backed slot radiator loaded with an AMC reflector," IEEE Transactions on Antennas and Propagation, vol. 60, no. 2, pp. 735-742, 2012.

[15] G. Goussetis, A. P. Feresidis, and J. C. Vardaxoglou, “Tailoring the AMC and EBG characteristics of periodic metallic arrays printed on grounded dielectric substrate," IEEE Transactions on Antennas and Propagation, vol. 54, no. 1, pp. 82-89, 2006.

[16] R. J. Langley and E. A. Parker, "Double square frequency selective surfaces and their equivalent circuit," Electronics Letters, vol. 19, no. 17, pp. 675-677, 1983.

[17] Y. Zhang, J. Von Hagen, M. Younis, C. Fischer, and W. Wiesbeck, "Planar artificial magnetic conductors and patch antennas," IEEE Transactions on Antennas and Propagation, vol. 51, no. 10 I, pp. 2704-2712, 2003.

[18] D. J. Kern, D. H. Werner, A. Monorchio, L. Lanuzza, and M. J. Wilhelm, "The design synthesis of multiband artificial magnetic conductors using high impedance frequency selective surfaces," IEEE Transactions on Antennas and Propagation, vol. 53, no. 1 I, pp. 8-17, 2005.

[19] Y. Seo, J. Jung, H. Lee, and Y. Lim, "Design of compact dualmeander antenna for WLAN operation," Microwave and Optical Technology Letters, vol. 54, no. 7, pp. 1595-1599, 2012. 

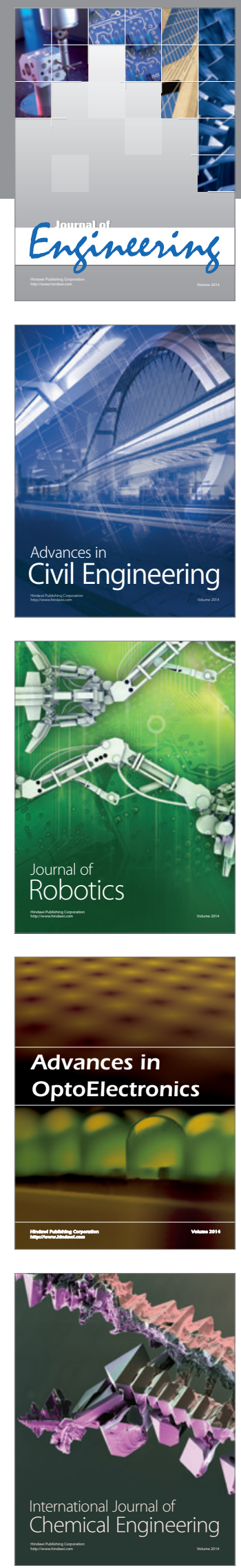

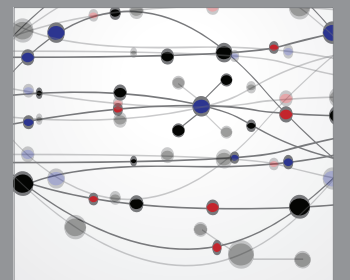

The Scientific World Journal
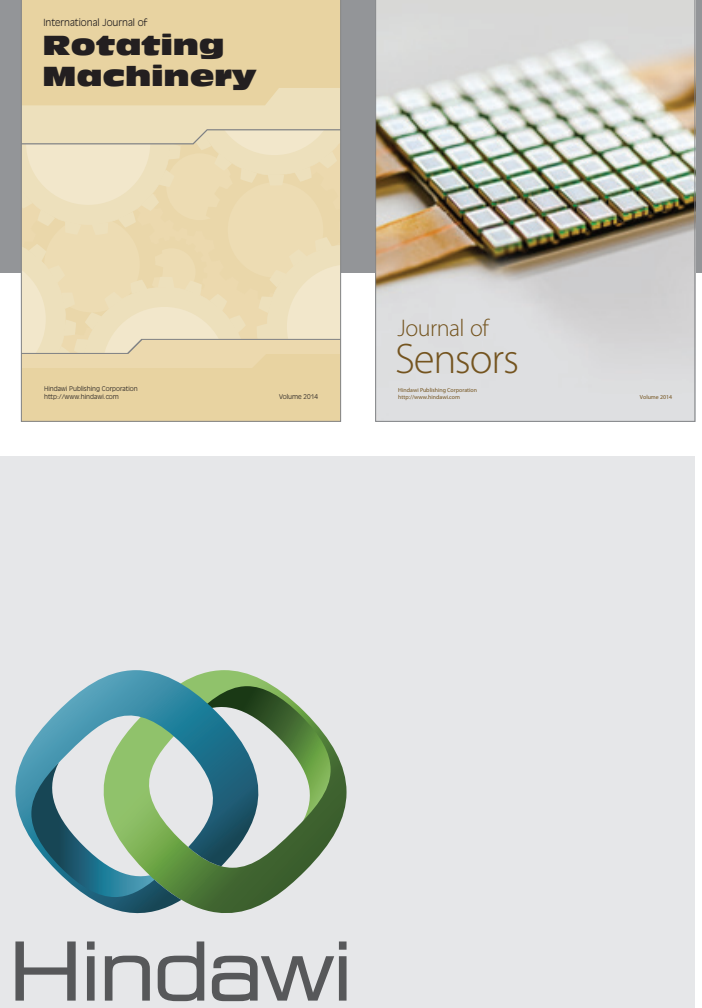

Submit your manuscripts at http://www.hindawi.com
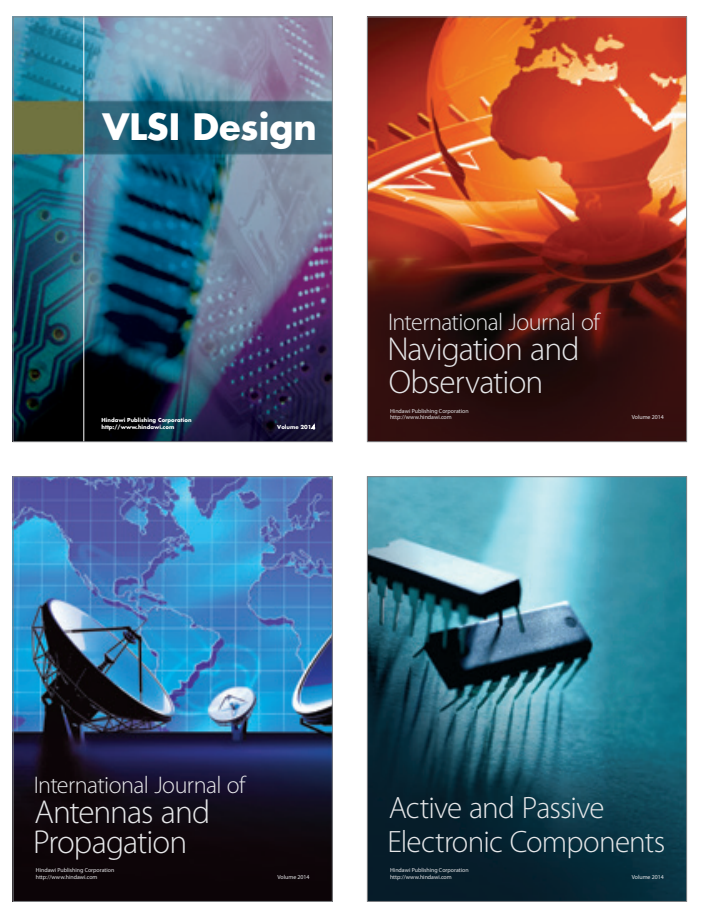
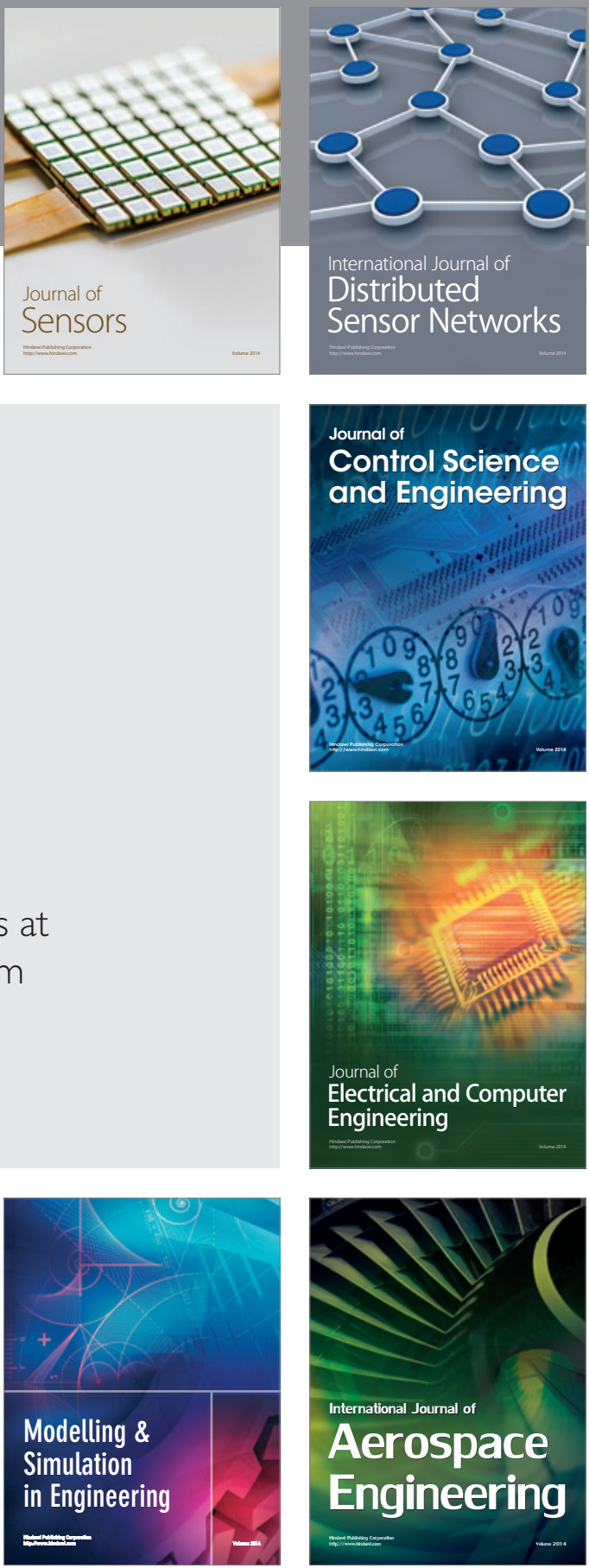

Journal of

Control Science

and Engineering
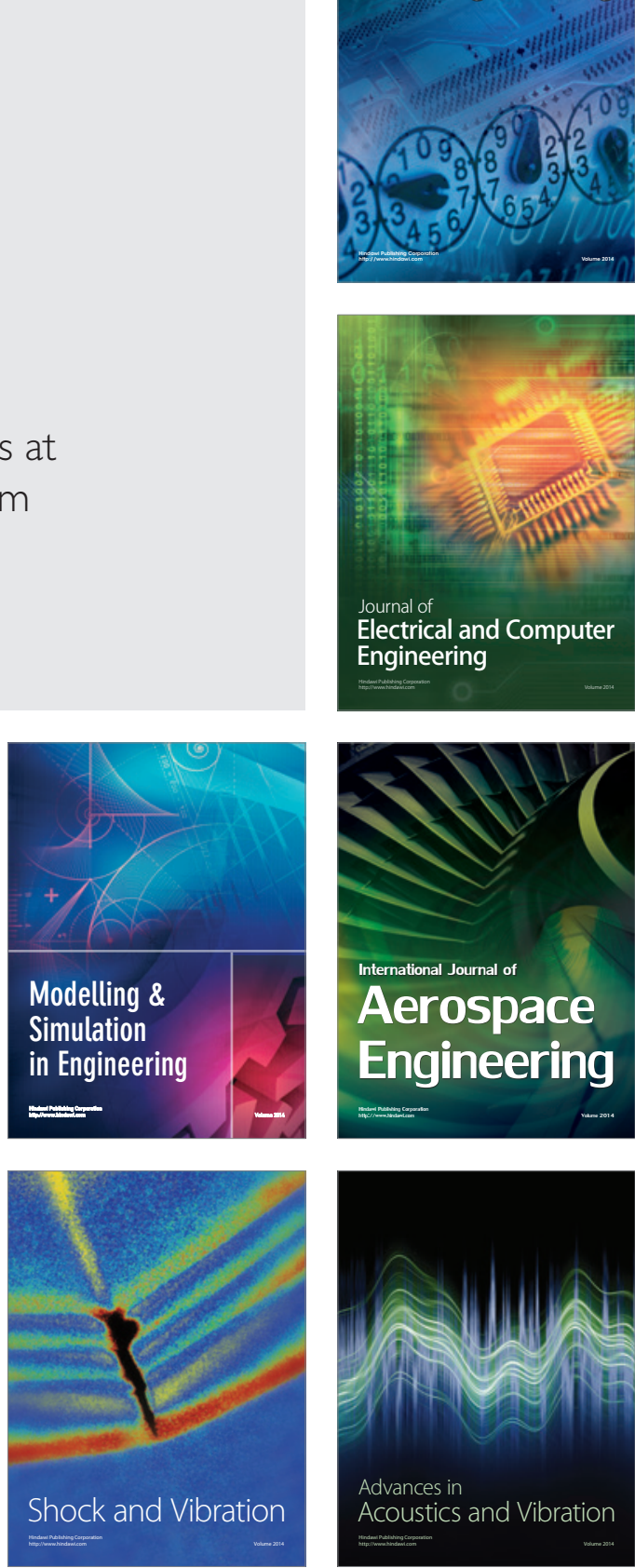